\title{
Adolescent alcohol use in Estonia compared to that in Latvia, Lithuania, Finland, and Sweden: results from cross-sectional surveys, 2003-2015
}

Daisy Kudre ( $\nabla$ daisykudre@gmail.com )

University of Tartu https://orcid.org/0000-0002-3505-0695

\section{Sigrid Vorobjov}

National Institute for Health Development

Kersti Pärna

University of Tartu

\section{Research article}

Keywords: adolescent alcohol use, underage drinking, risk behavior, Baltic countries, Nordic countries

Posted Date: April 30th, 2020

DOI: https://doi.org/10.21203/rs.3.rs-20729/v1

License: (c) (i) This work is licensed under a Creative Commons Attribution 4.0 International License.

Read Full License 


\section{Abstract}

Background: Patterns of alcohol use often start developing during adolescence and are associated with alcohol use and dependence during adulthood. The aims of the study were to describe trends in the prevalence of monthly alcohol use from 2003 to 2015 and to analyze the associations between alcohol use and family-related and school-related factors, risk behavioral factors and perceived alcohol availability in Estonia, Latvia, Lithuania, Finland, and Sweden.

Methods: The study used nationally representative data of 15-16-year-old adolescents from the European School Survey Project on Alcohol and Other Drugs (ESPAD). Data from Estonia, Latvia, Lithuania, Finland, and Sweden collected in 2003, 2007, 2011, and 2015 were utilized $(n=57,779)$. The prevalence of monthly alcohol use and light and strong alcohol use was calculated for each study year in all countries. A chi-square test for trend was used to evaluate statistically significant changes in alcohol use over the study period. Logistic regression analysis was performed to analyze the association between alcohol use and different factors. Fully adjusted odds ratios with $95 \%$ confidence intervals were calculated.

Results: Monthly alcohol use decreased significantly among 15-16-year-old boys and girls in Estonia, Latvia, Lithuania, Finland, and Sweden from 2003 to 2015. In 2015, the prevalence of monthly alcohol use among boys was $36.1 \%$ in Estonia, $44.3 \%$ in Latvia, 32.4\% in Lithuania, 32.3\% in Finland, and 22.4\% in Sweden, and among girls, it was $39.1 \%, 45.9 \%, 35.6 \%, 31.8 \%$, and $29.1 \%$, respectively. In Estonia, Latvia, Lithuania, and Sweden, girls had higher odds of monthly alcohol use than boys. In all countries, higher odds of monthly alcohol use were observed among adolescents who skipped school, smoked cigarettes, used cannabis, perceived alcohol to be easy to access and had parents who did not know always/often about their child's whereabouts on Saturday nights.

Conclusion: From 2003 to 2015, monthly alcohol use decreased in Estonia as well as in neighboring countries such as Latvia, Lithuania, Finland, and Sweden. The factors related to alcohol use in all five countries were generally similar. Based on the study results, health promotion and alcohol policy interventions could be improved to decrease and prevent alcohol use among adolescents.

\section{Background}

The harmful use of alcohol is a causal factor of more than 200 diseases and injury conditions, making it globally one of the leading risk factors for morbidity and mortality (1). Although the harmful effects of alcohol occur mostly during adulthood, patterns of alcohol use often start developing during adolescence and are associated with alcohol use and dependence during adulthood (2). Adolescent alcohol use is related to injuries, traffic accidents and suicide attempts $(3,4)$. Moreover, the early onset of alcohol use is associated with disruptions in brain development, which can lead to decreased performance related to attention, memory, and academic achievement (5). 
Estonia, Latvia, and Lithuania, also referred to as the three Baltic countries, are associated with high alcohol consumption, frequent binge drinking and early onset of alcohol use (6). After regaining independence in the beginning of the 1990s and then joining the European Union in 2004, the Baltic countries have experienced rapid economic growth. Regarding alcohol use, each country has implemented various policy mechanisms since the 1990 s to reduce alcohol availability, including raising the excise duty rates and limiting alcohol advertising and the times of off-premise sales of alcohol (6). However, between 2003 and 2015, alcohol policy in the Baltic countries remained more liberal than that in neighboring Nordic states such as Finland, Sweden, Norway, and Iceland, which are known for their strictly regulated alcohol markets $(7,8)$. In terms of Nordic countries, the current study focuses on Finland and Sweden, which are the two closest Nordic countries to the Baltic countries. Although the liberalization of alcohol policies occurred in both of these Nordic countries in the beginning of 1990s to make the policies consistent with the European Union rules, alcohol policy measures in these countries are still stricter than those in most other European countries (7). Similar to Baltic countries, in Finland and Sweden, heavy alcohol consumption $(9,10)$ and the early onset of alcohol use $(10)$ are common.

Adolescent alcohol use has been associated with sociodemographic, family-related, peer-related, and school-related factors $(11-13)$, as well as with other risk behaviors $(14,15)$ and perceived alcohol availability (13). In addition, associations have been found between alcohol use and national alcohol policy measures, such as pricing, availability, and marketing (16). However, the existing evidence on the relationship between adolescent alcohol use and risk factors has not been consistent across all risk factors. For example, existing studies have found positive, negative, and no relationships between adolescent alcohol use and family socioeconomic status (SES) (17). Furthermore, cross-cultural differences may exist in the direction and strength of the relationship between adolescent alcohol use and associated factors $(12,18)$.

The aims of this study were to describe trends in the prevalence of monthly alcohol use from 2003 to 2015 and to analyze the associations between alcohol use and family-related and school-related factors, other risk behaviors, and perceived alcohol availability in Estonia, Latvia, Lithuania, Finland, and Sweden.

\section{Methods}

\section{Setting and sampling}

This study used individual-level data of 15-16-year-old adolescents from the European School Survey Project on Alcohol and Other Drugs (ESPAD), which is a cross-sectional survey that has been performed every fourth year since 1995 in European countries. The results of the surveys are comparable between different countries, as the target population, questionnaires, data collection process, and data entry are standardized (19). In all countries, sampling is based on the school class as the final sampling unit. Questionnaires are anonymous and completed by schoolchildren in a classroom. However, since 2015, countries could opt to participate via an online survey (19). 
The present study utilized secondary data from Estonia, Latvia, Lithuania, Finland, and Sweden from $2003,2007,2011$, and 2015. All data are nationally representative (19-22), except for the data for Latvia in 2015 , as the school participation rate in Latvia was low during this year (49\% compared to the ESPAD average of $84 \%$ ), and consequently, the 2015 Latvian sample consisted of a low number of students (1,119 students compared to the ESPAD criterion of 2,400 students) (19).

\section{Measures}

\section{Alcohol-related variables}

Alcohol use was measured by the question 'On how many occasions (if any) have you had any alcoholic beverage to drink during the last 30 days?' The response options were ' 0 ', ' $1-2$ ', ' $3-5$ ', '6-9', '10-19', '2039 ', and ' $40+$ '. Based on the responses to this question, two groups were formed: 1) adolescents who did not consume alcohol (no) and 2) adolescents who consumed alcohol (yes).

Light alcohol use was assessed based on the following question that was asked separately for four different types of light alcoholic beverages: 'Think back to last 30 days. On how many occasions (if any) have you had any of the following to drink: beer, cider, alcopops, wine?' Two groups were formed: 1) adolescents who did not drink any of the types of light alcohol during the last 30 days (no) and 2) adolescents who consumed at least one type of light alcohol during the last 30 days (yes). As no comparable data on light alcohol use were available for 2003, only the results from 2007 to 2015 were used.

Strong alcohol use was measured by the following question: 'Think back to last 30 days. On how many occasions (if any) have you had any of the following to drink: spirits?' Based on this question, two groups were formed: 1) adolescents who did not consume strong alcohol (no) and 2) adolescents who consumed strong alcohol (yes).

\section{Study_year}

The study year referred to the year when the ESPAD survey was conducted: 2003, 2007, 2011, and 2015.

\section{Family-related factors}

Family SES was measured based on how adolescents rated their families' wealth compared to that of other families in the country. Answers were grouped into three categories: 1) better, 2) the same, and 3) worse than that of other families in Estonia.

Family structure referred to completeness of the family. Based on the answers, three groups were formed: 1) living with biological mother and father, 2) living with one biological parent, and 3) living without biological parents.

Rules outside of home indicated how often parents set definite rules about what adolescents could do outside the home. Answers were grouped into three categories: 1) always/often, 2) sometimes, and 3) 
seldom/never.

Regarding parents' knowledge about children's whereabouts on Saturday nights, three categories were formed: 1) always/often know, 2) sometimes know, and 3) usually don't know.

\section{$\underline{\text { School-related factors }}$}

Skipping school measured whether an adolescent had missed one or more lessons because of skipping

or 'cutting' school during the last 30 days. Two groups were formed: 1) adolescents who had not missed lessons (no) and 2) adolescents who had missed one or more lessons (yes).

\section{$\underline{\text { Risk behavior }}$}

Smoking referred to whether an adolescent had smoked cigarettes during the last 30 days. Two groups were formed: 1) adolescents who had not smoked (no) and 2) adolescents who had smoked one or more times (yes).

Cannabis use measured whether an adolescent had used marijuana or hashish (cannabis) during the last 30 days. Two groups were formed: 1) adolescents who had not used cannabis (no) and 2) adolescents who had used cannabis one or more times (yes).

Perceived alcohol availability

Perceived alcohol availability was calculated based on five separate questions measuring how difficult an adolescent thought it would be to obtain beer, cider, alcopops, wine, and spirits if they wanted.

Answers were divided into three groups: 1) easy, which indicated that the respondent thought it would be easy to obtain at least one of the alcoholic beverages; 2) difficult, which indicated that the respondent thought it would be difficult to obtain all alcohol beverages; and 3) don't know, which indicated that the respondent did not know how difficult it would be to obtain any of the alcohol beverages.

\section{Statistical analysis}

The prevalence of alcohol use, strong alcohol use and light alcohol use was calculated for every study year in all countries. A chi-square test for trend was used to evaluate statistically significant changes in alcohol use over the study period.

Logistic regression analysis was performed to analyze the associations between monthly alcohol use (yes vs no) and gender, study year, family-related factors, school-related factors, risk behavior, and perceived alcohol availability by country. Fully adjusted odds ratios (ORs) with 95\% confidence intervals (Cls) were calculated.

The questionnaires of respondents who did not provide answers to questions about the monthly alcohol use were excluded from the analysis $(n=767)$. The final study sample consisted of 57,779 15-16-year-old adolescents (49.0\% boys, 51.0\% girls) from Estonia $(n=9,559)$, Latvia $(n=8,672)$, Lithuania $(n=12,378)$, 
Finland $(n=15,889)$, and Sweden $(n=11,281)$. The questionnaires of respondents who did not provide answers to questions on light or strong alcohol use were excluded from the calculation of the prevalence of light or strong alcohol use $(n=417)$. The questionnaires of respondents who did not provide answers to questions on family-related factors, school-related factors, risk behavior, and perceived alcohol availability questions were excluded from the logistic regression analysis $(n=6,394)$.

Statistical analysis was conducted with Stata 14 (23).

\section{Results}

\section{Prevalence of alcohol use}

From 2003 to 2015, the prevalence of monthly alcohol use decreased significantly among boys and girls in Estonia, Latvia, Lithuania, Finland, and Sweden (Figure 1).

In 2015 , the prevalence of monthly alcohol use among boys was $36.1 \%(95 \% \mathrm{Cl} 33.4-38.8)$ in Estonia, 44.3\% (95\% Cl 40.1-48.5) in Latvia, 32.4\% (95\% Cl 29.9-35.0) in Lithuania, 32.3\% (95\% Cl 30.2-34.4) in Finland, and $22.4 \%(95 \% \mathrm{Cl} 20.1-24.7)$ in Sweden. The prevalence of monthly alcohol use among girls was 39.1\% (95\% Cl 36.3-41.8) in Estonia, 45.9\% (95\% Cl 41.8-50.1) in Latvia, 35.6\% (95\% Cl 32.9-38.3) in Lithuania, 31.8\% (95\% Cl 29.8-33.8) in Finland, and 29.1\% (95\% Cl 26.6-31.6) in Sweden (Figure 2).

The prevalence of light alcohol use decreased significantly among boys and girls in all countries from 2007 to 2015. The prevalence of strong alcohol use decreased significantly among boys and girls in Estonia, Lithuania, Finland, and Sweden but increased significantly among Latvian boys from 2003 to 2015. In all countries, the prevalence of light alcohol use was higher than the prevalence of strong alcohol use (Figure 3).

\section{Associations of monthly alcohol use with family-related factors, school-related factors, risk behavioral factors, and perceived alcohol availability}

Among adolescents in Estonia, Latvia, Lithuania, Finland, and Sweden, monthly alcohol use was associated with skipping school, smoking, cannabis use, perceived alcohol availability, and parents' knowledge about children's whereabouts on Saturday nights. Significant associations between alcohol use and gender, family SES, and family structure were observed in one or more countries (Table).

The adjusted logistic regression models showed that in Estonia, Latvia, Lithuania, and Sweden, girls had significantly higher odds of monthly alcohol use than boys. In Estonia, Latvia, Lithuania, Finland, and Sweden, adolescents who had skipped school, smoked cigarettes, or used cannabis during the last 30 days had higher odds of alcohol use than adolescents who had not skipped school, smoked cigarettes, or used cannabis. In all analyzed countries, adolescents who perceived alcohol to be easily accessible had higher odds of alcohol use (Table). 
In Latvia, Lithuania, Finland, and Sweden, adolescents with worse family SES had lower odds of alcohol use than adolescents with better family SES. Furthermore, in Finland and Sweden, adolescents with the same family SES as other families in their countries had lower odds of alcohol use than adolescents who had better family SES. In Estonia, no statistically significant associations were found between alcohol use and family SES (Table).

In Finland and Sweden, adolescents living with one biological parent (vs two biological parents) had higher odds of alcohol use. In Estonia and Lithuania, adolescents living without any biological parents (vs two biological parents) had lower odds of alcohol use, whereas in Sweden, adolescents living without any biological parents (vs two biological parents) had higher odds of alcohol use (Table).

In Latvia, adolescents whose parents sometimes set rules outside of the home ( $v s$ always/often) had higher odds of alcohol use, whereas no significant association was found in other countries (Table).

\section{Discussion}

This study focused on adolescent alcohol use and related factors in Estonia compared to that in Latvia, Lithuania, Finland, and Sweden from 2003 to 2015.

\section{Monthly alcohol use}

From 2003 to 2015, the prevalence of alcohol use decreased significantly among 15-16-year-old girls and boys in Estonia and neighboring countries. The decrease was the largest among boys and girls in Lithuania and boys in Sweden, among whom monthly alcohol use showed a more than twofold decline. Estonia showed a similar change as Finland, where monthly alcohol use decreased 1.6 times among boys and 1.7 times among girls. While the prevalence of light alcohol use decreased significantly in all countries, strong alcohol use decreased in all countries except Latvia, where an upward trend among boys was found.

The findings are consistent with the existing evidence that shows that while adolescent alcohol use increased during the 1990s (19), it has been decreasing in many countries in Europe and North America since the beginning of the 2000s (24). Among the 25 countries participating in the ESPAD from 2003 to 2015 , the average decrease in the prevalence of monthly alcohol use was 1.3 times among boys and girls (19). This finding implies that the change in alcohol use in Latvia was similar to the ESPAD average, but the decreases in Estonia, Lithuania, Finland, and Sweden were higher than the ESPAD average.

The reasons behind the decrease in adolescent alcohol use are considered to be an increased awareness

of the harmful effects of alcohol; effective use of alcohol prevention programs targeting adolescents; and a shift in social norms, attitudes, and the social environment $(24,25)$. Furthermore, the beginning of the 21 st century has been associated with a general shift towards a decline in risk behavior, including smoking, drug use, and sexual risk behavior (24). However, although adolescent alcohol and smoking 
show a declining trend, cannabis use has remained stable or shown an upward trend in several countries in Europe (19).

In 2015, the prevalence of monthly alcohol use among boys and girls in Estonia was lower than that in Latvia, similar to that Lithuania and higher than that in Sweden. Compared to that in Finland, the prevalence of monthly alcohol use in Estonia was similar among boys but higher among girls. In all countries, the prevalence of light alcohol use was higher than the prevalence of strong alcohol use. Interestingly, different patterns were found between countries based on alcohol type. Among boys and girls in Latvia and Lithuania, the prevalence of monthly light alcohol use in 2015 was more than two times higher than the prevalence of strong alcohol use, whereas in Estonia, Finland, and Sweden, the difference between the prevalence of light and strong alcohol use was less than 1.7 times. Therefore, it seems that adolescents in Latvia and Lithuania prefer light alcohol over strong alcohol more than adolescents in Estonia, Finland, and Sweden. This study did not evaluate the associations between adolescent alcohol use and policy measures; however, in many countries, different measures often apply to light and strong alcohol. For example, higher excise duties apply to strong alcohol than light alcohol in the countries analyzed (26). Furthermore, in Finland and Sweden during the study period, strong alcohol was sold only by national alcohol stores with strict limitations on age, time and location of sale, whereas some light alcohol (below 4.7 vol. \% in Finland and 3.5 vol. \% in Sweden) was sold at supermarkets or other consumer sale outlets (27). In Estonia, Latvia, and Lithuania, restrictions on age, time and location of sale were consistent for both light and strong alcohol during the study period (26). As adolescent alcohol use is associated with national alcohol policy measures such as pricing, availability, and marketing (16), further studies could examine how different policy measures are associated with adolescent light and strong alcohol use.

\section{Associations of alcohol use with different factors}

A fully adjusted logistic regression model confirmed that in Estonia, Latvia, Lithuania, and Sweden, girls had significantly higher odds of alcohol use than boys. Gender differences remained nonsignificant in Finland. As girls are more vulnerable to negative consequences of alcohol use than boys $(28,29)$, prevention methods should particularly focus on reducing alcohol use among girls.

The current study showed a significant association between alcohol use and skipping school in all countries, which is supported by the existing literature, as school misbehavior, such as skipping class, has been found to be a correlate of adolescent alcohol use (30). Furthermore, the current study showed strong associations between alcohol use and other risk behaviors, such as smoking and cannabis use. Although current evidence suggests that adolescents who are heavy cannabis users may use alcohol and cannabis concurrently (31), the prevalence of the simultaneous use of alcohol and cannabis is common among adolescents (31) as well as adults (32). Therefore, prevention methods could simultaneously target alcohol and cannabis use as well as smoking to reduce risky behavior among adolescents.

Despite cross-national differences in alcohol policies, alcohol use was strongly related to perceived alcohol availability in all countries. Similar associations have been reported in the existing literature 
$(12,13)$.

Regarding family-related factors, associations varied between countries. Estonia was the only country that showed no significant association between alcohol use and family SES. In Latvia, Lithuania, Finland, and Sweden, adolescents with worse family SES had lower odds of alcohol use than adolescents with better family SES. However, these findings should be interpreted with caution as existing studies conclude that the direction of the association between alcohol use and family SES may vary depending on the measure used to assess family SES (17).

The existing literature suggests that adolescent alcohol use is associated with living in non-intact families (33), and in this study, such an association was found in Finland and Sweden. Interestingly, in Estonia and Lithuania, adolescents living without any biological parents had significantly lower odds of alcohol use than adolescents living with two biological parents. However, the percentage of adolescents living without any biological parents was small (approximately $5 \%$ in both countries), and the current study did not explore whether they lived alone or with one or two stepparents or grandparents. Therefore, in-depth analysis of association between alcohol use and adolescents living with no biological parents could be conducted.

Adolescent alcohol use has also been associated with parental control and rules $(11,13,34)$. In the current study, all countries showed a significant association between alcohol use and parents' knowledge about children's whereabouts on Saturday nights. However, a significant association between parents who set clear rules about what adolescents could do outside of the home and a lower odds of adolescent alcohol use was found only in Latvia.

The main limitations of the study were related to the study design. The ESPAD is a cross-sectional survey, so no causal inferences could be made. Furthermore, the findings were based on self-reported measures, which may have resulted in reporting bias and the potential underreporting of sensitive health-related data (35). This study did not include other factors potentially associated with alcohol use (e.g., peerrelated factors), as there were minor differences between questions included in different countries in each study year. Despite the limitations, this study effectively compared alcohol use across different countries, as similar methodologies were used in all countries in every study year.

\section{Conclusion}

In conclusion, monthly alcohol use decreased significantly among 15-16-year-old boys and girls in Estonia, Latvia, Lithuania, Finland, and Sweden from 2003 to 2015. Whereas monthly light alcohol use decreased among boys and girls in all countries, monthly strong alcohol use decreased in all countries except Latvia, where it increased among boys.

The directions of the associations between alcohol use and risk factors in Estonia and the neighboring countries were generally similar. In all countries, higher monthly alcohol use was observed among adolescents who skipped school, smoked cigarettes, used cannabis, perceived alcohol to be easy to 
access and had parents who did not know always/often about their child's whereabouts on Saturday nights. However, some differences occurred between countries. Monthly alcohol use was higher among girls than boys in Estonia, Latvia, Lithuania and Sweden, but not in Finland. In all countries except Estonia, higher alcohol use was associated with better family SES. Different associations were found across countries between alcohol use and family structure as well as rules set by parents. Based on the study results, health promotion and alcohol policy interventions could be improved to decrease and prevent alcohol use among adolescents.

\section{Abbreviations}

ESPAD - the European School Survey Project on Alcohol and Other Drugs

Family SES - family socioeconomic status

ORs - odds ratios

Cls - confidence intervals

\section{Declarations}

Ethics approval and consent to participate

In this study, secondary data from Estonia Latvia, Lithuania, Finland and Sweden were used. All ESPAD surveys were administered in accordance with national ethical standards and with the Declaration of Helsinki. We asked permission to use the data from the ESPAD coordination center and, therefore, for secondary analysis, the ethical committee's approval was not necessary.

Consent for publication

Not applicable

Availability of data and materials

The datasets for Estonia Latvia, Lithuania, Finland and Sweden analyzed in this study are available from the international coordinator of the ESPAD on reasonable request.

Competing interests

The authors declare that they have no competing interests.

Funding

This work was supported by the Estonian Research Council (grant number IUT34-17). The funding body played no role in the design of the study and collection, analysis, interpretation of data, or writing the 
manuscript.

Authors' contributions

DK contributed to the study design, data analysis, interpretation of the data, and writing of the paper. SV and KP contributed to the study design, data analysis, interpretation of the data and editing of the paper. All authors read and approved the final manuscript.

Acknowledgements

The authors would like to acknowledge the members of the ESPAD group who collected the national data (http://www.espad.org/report/acknowledgements).

\section{References}

1. Laatikainen L, Fleischmann A, Gmel G, Jernigan D, Poznyak V, Rehm J, et al. Alcohol and public health. In: Poznyak V, Rekve D, editors. Global status report on alcohol and health - 2014 ed. Geneva: WHO; 2014. p. 2-26.

2. McCambridge J, McAlaney J, Rowe R. Adult consequences of late adolescent alcohol consumption: a systematic review of cohort studies. PLoS Med 2011;8:1-13.

3. Sindelar HA, Barnett NP, Spirito A. Adolescent alcohol use and injury. A summary and critical review of the literature. Minerva Pediatr 2004;56:291-310.

4. Martiniuk ALC, Chen HY, Glozier N, Patton G, Senserrick T, Williamson A, et al. High alcohol use a strong and significant risk factor for repetitive self-harm in female and male youth: a prospective cohort study. Am J Drug Alcohol Abuse 2015;41:465-73.

5. Squeglia LM, Jacobus J, Tapert SF. The effect of alcohol use on human adolescent brain structures and systems. Handb Clin Neurol 2014;125:501-10.

6. Trapencieris M, Sniķere S. Alcohol availability and affordability in Latvia. In: Moskalewicz J, Österberg E, editors. Changes in alcohol affordability and availability. Twenty years of transitions in Eastern Europe. Helsinki: National Institute for Health and Welfare; 2016. p. 86-100.

7. Karlsson T. Nordic alcohol policy in Europe. The adaptation of Finland's, Sweden's and Norway's alcohol policies to a new policy framework, 1994-2013 [dissertation]. Vasa: Åbo Akademi University; 2014.

8. Pärna, K. Alcohol consumption and alcohol policy in Estonia 2000-2017 in the context of Baltic and Nordic countries. Drug Alcohol Rev 2019; doi: 10.1111/dar.13008.

9. Rehm J, Taylor B, Patra J. Volume of alcohol consumption, patterns of drinking and burden of disease in the European regioon 2002. Open Addiction J 2006;101:1086-95.

10. Järvinen $M$, Room R. Youth drinking cultures: European experiences. In: Järvinen M, Room R, editors. Youth drinking cultures: European experiences. London: Routledge; 2007. 
11. Guillén N, Roth E, Alfaro A, Fernandez E. Youth alcohol drinking behavior: associated risk and protective factors. Rev iberoam psicol salud 2015;6:53-63.

12. Beyers JM, Toumbourou JW, Catalano RF, Arthur MW, Hawkins JD. A cross-national comparison of risk and protective factors for adolescent substance use: the United States and Australia. J Adolesc Health 2004;35:3-16.

13. Arthur MW, Hawkins JD, Pollard JA, Catalano RF, Baglioni Jr JA. Measuring risk and protective factors for substance use, delinquency, and other adolescent problem behaviors. The communities that care youth survey. Eval Rev 2002;26:575-601.

14. Orlando M, Tucker JS, Ellickson PL, et al. Concurrent use of alcohol and cigarettes from adolescence to young adulthood: an examination of developmental trajectories and outcomes. Subst Use Misuse 2005;40:1051-69.

15. Raposo JCS, Costa ACQ, Valença PAM, Zarzar PM, Diniz ADS, Colares V, et al. Binge drinking and illicit drug use among adolescent students. Rev Saude Publica 2017;51:83.

16. Noel JK. Associations between alcohol policies and adolescent alcohol use: a pooled analysis of GSHS and ESPAD data. Alcohol Alcohol 2019;54:639-46.

17. Hanson MD, Chen AE. Socioeconomic status and health behaviors in adolescence: a review of the literature. J Behav Med 2007;30:263-85.

18. Adler I, Kandel DB. A cross-cultural comparison of sociopsychological factors in alcohol use among adolescents in Israel, France, and the United States. J Youth Adolesc 1982;11:89-113.

19. Guttormsson U, Leifman H, Kraus L, Arpa S, Molinaro S, Monshouwer K, Trapencieris M, Vicente J, Englund A, Svensson J, editors. ESPAD 2015 methodology. Luxembourg: Publication office of the European Union; 2016.

20. Hibell B, Andersson B, Bjarnason T, Ahlström S, Balakireva O, Kokkevi A, Morgan M, editors. The ESPAD report 2003. Alcohol and other drug use among students in 35 countries. Stockholm: The Swedish Council for Information on Alcohol and Other Drugs, CAN; 2004.

21. Hibell B, Guttormsson U, Ahlström S, Balakireva O, Bjarnason T, Kokkevi A, Kraus L, editors. The 2007 ESPAD report. Substance use among students in 35 European countries. Stockholm: The Swedish Council for Information on Alcohol and Other Drugs, CAN; 2009.

22. Hibell B, Guttormsson U, Ahlström S, Balakireva O, Bjarnason T, Kokkevi A, Kraus L, editors. The 2011 ESPAD report. Substance use among students in 36 European countries. Stockholm: The Swedish Council for Information on Alcohol and Other Drugs, CAN; 2012.

23. 2015. Stata Statistical Software: Release 14. College Station, TX: StataCorp LP.

24. de Looze M, Baska T, Vieno A, Pavlova D. Alcohol use. In: Inchley J, Currie D, Young T, Samdal O, Torsheim T, Augustson L, Mathison F, Aleman-Diaz A, Molcho M, Weber M, Barnekow V, editors. Growing up unequal: gender and socioeconomic differences in young people's health and well-being. Health behaviour in school-aged children (HBSC) study: international report from the 2013/2014 survey. Copenhagen: World Health Organization; 2016. 
25. Pennay A, Livingston $M$, MacLean S. Young people are drinking less: It is time to find out why. Drug Alcohol Rev 2015;34:115-8.

26. Orro E, Martens K, Lepane L, Josing M, Reiman M, Eds. Alkoholi turg, tarvimine ja kahjud Eestis. Aastaraamat 2015. Tallinn: Eesti Konjuktuuriinstituut; 2015.

27. Hallberg J, Österberg E. Information on the Nordic alcohol market 2015. Helsinki: Alco Inc., National Institute for Health and Welfare; 2015.

28. Squeglia LM, Jacobus J, Tapert SF. The effect of alcohol use on human adolescent brain structures and systems. Handb Clin Neurol 2014;125:501-10.

29. Stewart SH, Gavric D, Collins P. Women, girls, and alcohol. In: Brady KT, Back SE, Greenfield SF, editors. Women and Addiction. New York: The Guildford Press; 2009. p. 342-359.

30. Wiers RW, Fromme K, Latvala A, Stewart S. Risk and protective factors for underage drinking. In: De Witte $\mathrm{P}$, Mitchell Jr MC, editors. Underage drinking. Louvain-la-Neuve: Presses universitaires de Louvain; 2012. p. 79-146.

31. Patton GC, Coffey C, Lynskey MT, Reid S, Hemphill S, Carlin JB, Hall W. Trajectories of adolescent alcohol and cannabis use into young adulthood. Addiction 2007;102:607-15.

32. Subbaraman MS, Kerr WC. Simultaneous versus concurrent use of alcohol and cannabis in the national alcohol survey. Alcohol Clin Exp Res 2015;39:872-9.

33. Bjarnason T, Andersson B, Choquet M, Elekes Z, Morgan M, Rapinett G. Alcohol culture, family structure and adolescent alcohol use: multilevel modeling of frequency of heavy drinking among 1516 year old students in 11 European countries. J Stud Alcohol 2003;64:200-8.

34. Habib C, Santoro J, Kremer P, Toumbourou J, Leslie E, Williams J. The importance of family management, closeness with father and family structure in early adolescent alcohol use. Addiction 2010;105:1750-8.

35. Newell SA, Girgis A, Sanson-Fischer RW, Savolainen NJ. The accuracy of self-reported health behaviors and risk factors relating to cancer and cardiovascular disease in the general population: a critical review. Am J Prev Med 1999;17:211-29.

\section{Table}

Table. Associations of monthly alcohol use and descriptive factors among 15-16-year-old adolescents in Estonia, Latvia, Lithuania, Finland, and Sweden based on data from the ESPAD study. 
Variables

\begin{tabular}{|c|c|c|c|c|}
\hline Estonia & Latvia & Lithuania & Finland & Sweden \\
\hline $\begin{array}{l}\mathrm{OR} *(95 \% \\
\mathrm{Cl})\end{array}$ & $\begin{array}{l}\mathrm{OR} *(95 \% \\
\mathrm{Cl})\end{array}$ & $\begin{array}{l}\mathrm{OR} *(95 \% \\
\mathrm{Cl})\end{array}$ & $\begin{array}{l}\mathrm{OR} *(95 \% \\
\mathrm{Cl})\end{array}$ & $\begin{array}{l}\mathrm{OR} *(95 \% \\
\mathrm{Cl})\end{array}$ \\
\hline
\end{tabular}

Gender

$\begin{array}{llllll}\text { Boys } & 1 & 1 & 1 & 1 & 1 \\ \text { Girls } & \mathbf{1 . 3 0} & \mathbf{1 . 2 2} & \mathbf{1 . 2 8} & 1.04 & \mathbf{1 . 1 1} \\ & \mathbf{( 1 . 1 8 - 1 . 4 4 )} & \mathbf{( 1 . 1 0 - 1 . 3 6 )} & \mathbf{( 1 . 1 7 - 1 . 4 0 )} & (0.96-1.12) & \mathbf{( 1 . 0 0 - 1 . 2 2 )}\end{array}$

Skipping school

$\begin{array}{llllll}\text { No } & 1 & 1 & 1 & 1 & 1 \\ \text { Yes } & 1.66 & 1.48 & 1.62 & 1.65 & 1.76 \\ & (\mathbf{1 . 4 9 - 1 . 8 6 )} & (\mathbf{1 . 3 2}-1.66) & \mathbf{( 1 . 4 7 - 1 . 7 9 )} & \mathbf{( 1 . 4 9 - 1 . 8 2 )} & \mathbf{( 1 . 5 5 - 2 . 0 1 )}\end{array}$

Smoking

$\begin{array}{llllll}\text { No } & 1 & 1 & 1 & 1 & 1 \\ \text { Yes } & \mathbf{5 . 0 2} & \mathbf{4 . 8 4} & \mathbf{3 . 8 2} & \mathbf{5 . 7 7} & \mathbf{7 . 0 9} \\ & (\mathbf{4 . 4 1 - 5 . 7 2 )} & \mathbf{( 4 . 2 8 - 5 . 4 8 )} & \mathbf{( 3 . 4 2 - 4 . 2 7 )} & \mathbf{( 5 . 2 5 - 6 . 3 5 )} & \mathbf{( 6 . 1 5 - 8 . 1 9 )}\end{array}$

Cannabis use

$\begin{array}{llllll}\text { No } & 1 & 1 & 1 & 1 & 1 \\ \text { Yes } & \mathbf{2 . 1 8} & \mathbf{2 . 9 3} & \mathbf{2 . 4 4} & \mathbf{3 . 8 2} & \mathbf{2 . 2 9} \\ & (\mathbf{1 . 6 7 - 2 . 8 5 )} & \mathbf{( 1 . 9 6 - 4 . 3 8 )} & \mathbf{( 1 . 7 8 - 3 . 3 4 )} & \mathbf{( 2 . 4 2 - 6 . 0 2 )} & \mathbf{( 1 . 4 5 - 3 . 6 2 )}\end{array}$

Perceived alcohol availability

$\begin{array}{llllll}\text { Difficult } & 1 & 1 & 1 & 1 & 1 \\ \text { Easy } & 3.46 & 3.58 & 2.69 & \mathbf{5 . 2 9} & \mathbf{5 . 3 7} \\ & (2.95-4.05) & (3.02-4.24) & (2.34-3.09) & (4.54-6.17) & (4.18-6.90) \\ \text { Don't know } & 0.68 & 0.99 & \mathbf{0 . 6 9} & \mathbf{0 . 4 7} & \mathbf{0 . 5 9} \\ & (0.51-0.92) & (0.70-1.38) & (0.53-0.90) & (0.35-0.63) & (0.38-0.92)\end{array}$

Family SES compared to that of other families in the country

$\begin{array}{llllll}\text { Better } & 1 & 1 & 1 & 1 & 1 \\ \text { Same } & 0.93 & 0.98 & 0.94 & 0.90 & \mathbf{0 . 8 6} \\ & (0.84-1.04) & (0.88-1.10) & (0.84-1.04) & (\mathbf{0 . 8 2 - 0 . 9 9 )} & \mathbf{( 0 . 7 8 - 0 . 9 5 )} \\ \text { Worse } & 0.85 & \mathbf{0 . 8 2} & \mathbf{0 . 8 0} & \mathbf{0 . 8 3} & \mathbf{0 . 7 3} \\ & (0.72-1.01) & \mathbf{( 0 . 6 8 - 1 . 0 0 )} & \mathbf{( 0 . 6 9 - 0 . 9 2 )} & \mathbf{( 0 . 7 1 - 0 . 9 6 )} & \mathbf{( 0 . 5 8 - 0 . 9 2 )}\end{array}$

Family structure 


\begin{tabular}{|c|c|c|c|c|c|}
\hline Mother or father & $\begin{array}{l}1.01 \\
(0.91-1.13)\end{array}$ & $\begin{array}{l}1.05 \\
(0.93-1.18)\end{array}$ & $\begin{array}{l}0.94 \\
(0.84-1.04)\end{array}$ & $\begin{array}{l}1.25 \\
(1.14-1.37)\end{array}$ & $\begin{array}{l}1.19 \\
(1.05-1.34)\end{array}$ \\
\hline $\begin{array}{l}\text { Neither mo } \\
\text { nor father }\end{array}$ & $\begin{array}{l}0.76 \\
(0.58-0.99)\end{array}$ & $\begin{array}{l}0.83 \\
(0.67-1.01)\end{array}$ & $\begin{array}{l}0.80 \\
(0.69-0.92)\end{array}$ & $\begin{array}{l}1.46 \\
(0.99-2.15)\end{array}$ & $\begin{array}{l}1.12 \\
(0.81-1.55)\end{array}$ \\
\hline
\end{tabular}

Rules outside of the home

\begin{tabular}{llllll}
\hline Always/often & 1 & 1 & 1 & 1 & 1 \\
\hline Sometimes & 1.08 & $\mathbf{1 . 1 8}$ & 1.05 & 1.02 & 0.96 \\
& $(0.93-1.26)$ & $\mathbf{( 1 . 0 3 - 1 . 3 6 )}$ & $(0.93-1.18)$ & $(0.93-1.11)$ & $(0.85-1.09)$ \\
\hline Seldom/never & 1.05 & $\mathbf{1 . 2 5}$ & 1.03 & 0.97 & 0.95 \\
& $(0.92-1.20)$ & $\mathbf{( 1 . 1 0 - 1 . 4 2 )}$ & $(0.93-1.15)$ & $(0.87-1.07)$ & $(0.85-1.07)$ \\
\hline
\end{tabular}

Parents know about child's whereabouts on Saturday nights

\begin{tabular}{clllll}
\hline Always/often know & 1 & 1 & 1 & 1 & 1 \\
\hline Sometimes know & 1.66 & 1.63 & 1.96 & 2.73 & 2.60 \\
& $(1.45-1.90)$ & $(1.38-1.91)$ & $(1.69-2.28)$ & $(2.41-3.11)$ & $(2.19-3.08)$ \\
\hline Usually don't know & 1.93 & 1.45 & 1.79 & 2.97 & 2.11 \\
& $(1.53-2.44)$ & $(1.12-1.89)$ & $(1.41-2.26)$ & $(2.38-3.71)$ & $(1.56-2.85)$
\end{tabular}

* Adjusted to all variables in the table and the study year

Figures 


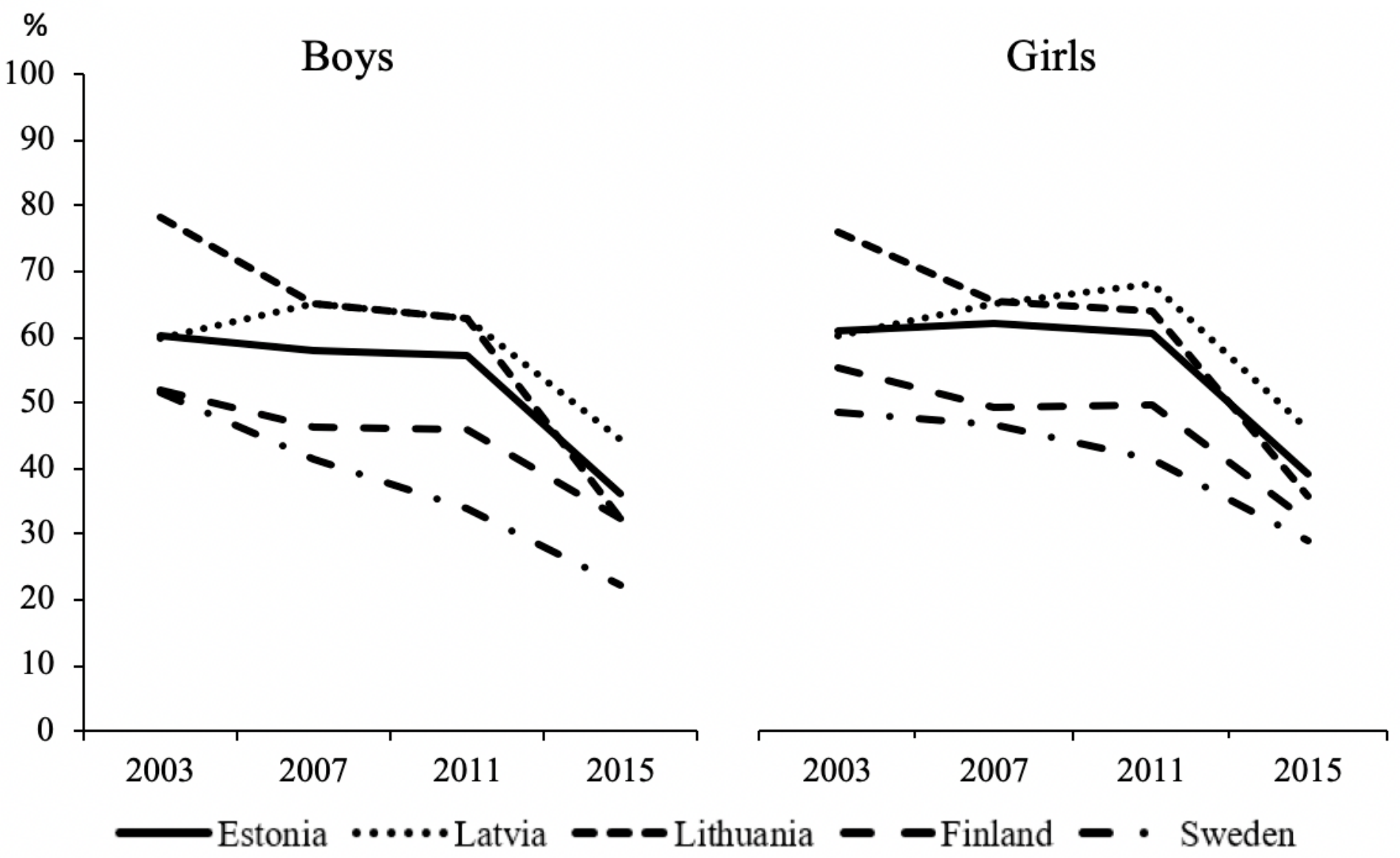

Figure 1

Prevalence of monthly alcohol use among 15-16-year-old boys and girls in Estonia, Latvia, Lithuania, Finland, and Sweden. All trends were statistically significant $(p<0.001$; Latvian girls, $p=0.022)$. 


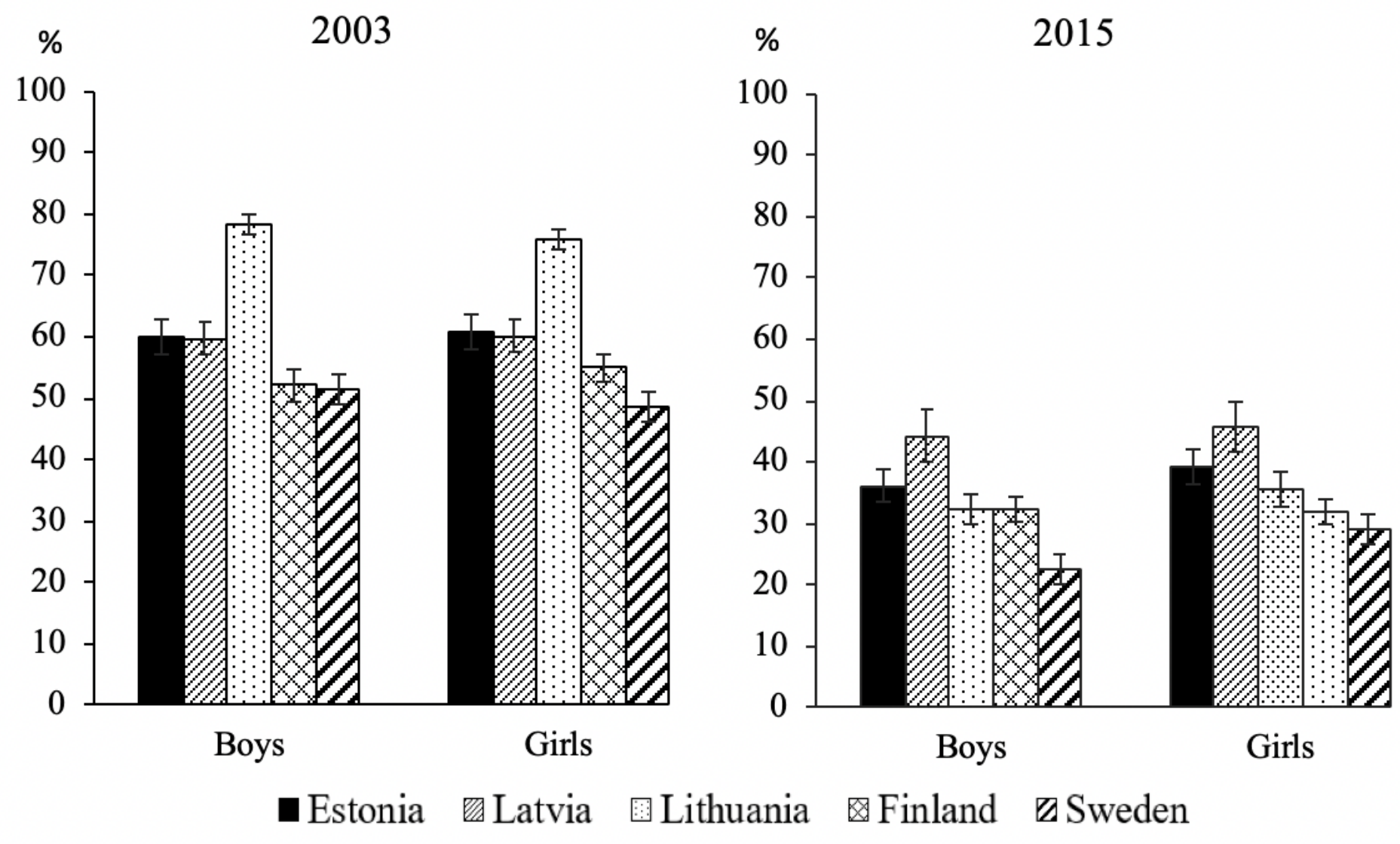

Figure 2

Prevalence of monthly alcohol use among 15-16-year-old boys and girls in Estonia, Latvia, Lithuania, Finland, and Sweden in 2003 and 2015. 


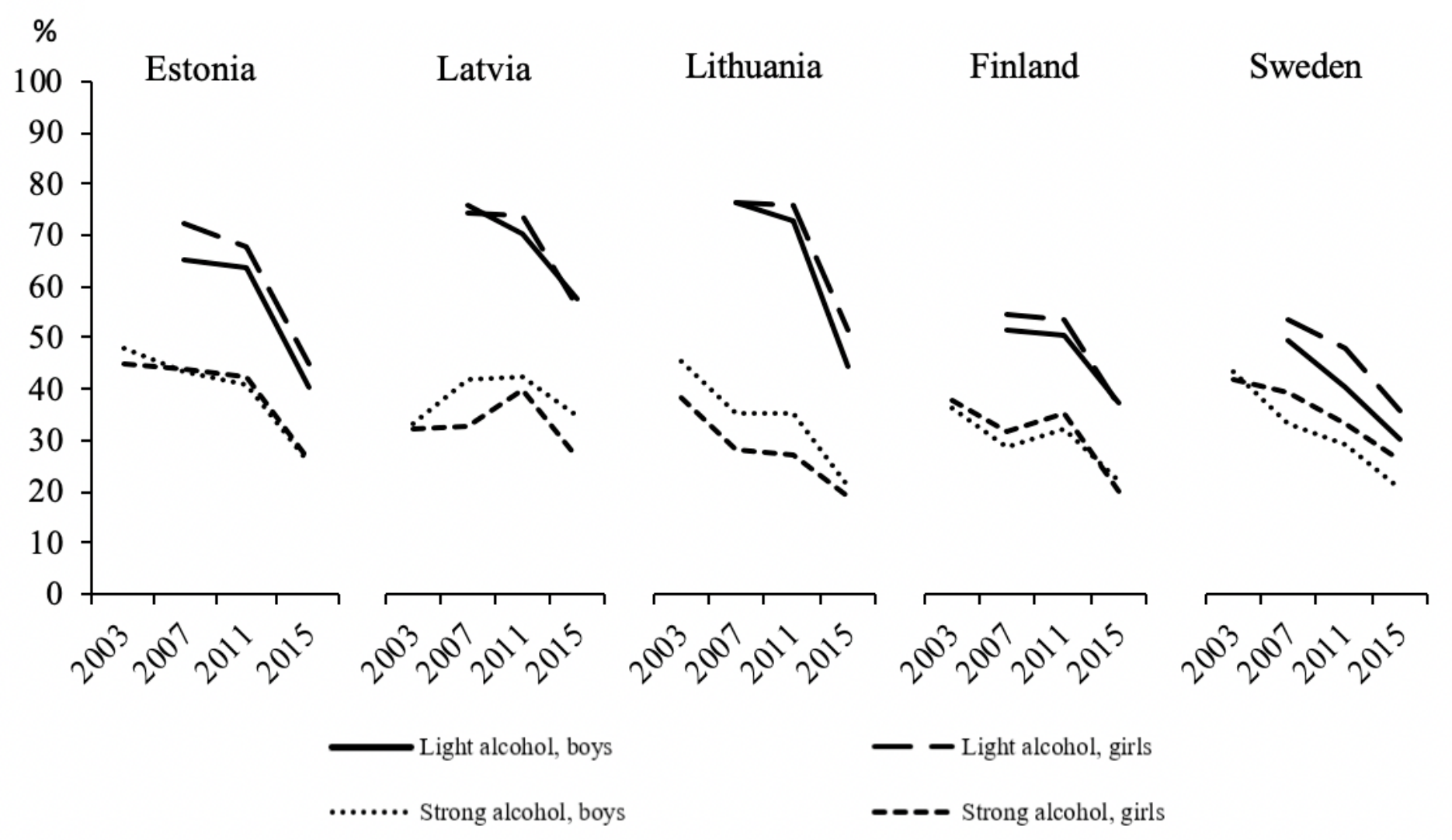

\section{Figure 3}

Prevalence of monthly light and strong alcohol use among 15-16-year-old boys and girls in Estonia, Latvia, Lithuania, Finland, and Sweden. ESPAD 2003-2015. All changes in light alcohol use from 2007 to 2015 were statistically significant $(p<0.001)$. Changes in strong alcohol use from 2003 to 2015 were statistically significant among boys and girls in Estonia, Lithuania, Finland, and Sweden $(p<0.001)$ and among boys in Latvia $(\mathrm{p}=0.013)$. 